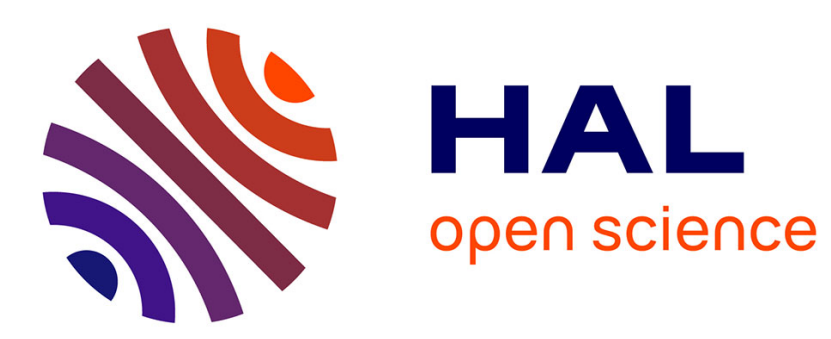

\title{
Memorisation of Information from Scientific movies
}

Bulent Pekdag, Jean-François Le Maréchal

\section{To cite this version:}

Bulent Pekdag, Jean-François Le Maréchal. Memorisation of Information from Scientific movies. Roser Pintó and Digna Couso. Springer: Dordrecht, The Netherlands., pp.12, 2007. hal-00267572

\section{HAL Id: hal-00267572 \\ https://hal.science/hal-00267572}

Submitted on 27 Mar 2008

HAL is a multi-disciplinary open access archive for the deposit and dissemination of scientific research documents, whether they are published or not. The documents may come from teaching and research institutions in France or abroad, or from public or private research centers.
L'archive ouverte pluridisciplinaire HAL, est destinée au dépôt et à la diffusion de documents scientifiques de niveau recherche, publiés ou non, émanant des établissements d'enseignement et de recherche français ou étrangers, des laboratoires publics ou privés. 


\title{
Memorisation of Information from Scientific movies
}

\author{
Bülent PEKDAĞ \& Jean-François Le MARÉCHAL \\ UMR ICAR-coast, Université Lyon 2, ENS-LSH, ENS-Lyon, CNRS, INRP - France

\begin{abstract}
lemarech@ens-lyon.fr
\end{abstract}
Bülent PEKDAĞ \& Jean-François LE MARÉCHAL (2007). Memorisation of Information from Scientific Movies. In Roser Pintó and Digna Couso (Eds.), Contributions from Science Education Research (p. 199-210). Springer: Dordrecht, The Netherlands.

\section{Introduction}

Chemical movies have been used in teaching situations since the late 1950's (Slabaugh \& Hatch, 1958) and huge efforts were done to produce more and more movies. The use of such movies has evolved and diversified during the second part of the 20th century (Pekdağ \& Le Maréchal, submitted). Movies to prepare laboratory work have been proposed to students (Rouda, 1973). Later, movies of experiments have been produced for demonstrations in several domains of chemistry (Jacobsen et al., 2002 and references herein). In most cases, students had to watch one movie prescribed by the teacher. We decided to provide students with a bank of movies and to let them chose the movie(s) they needed according to a task they had to accomplish. The use of such a bank is the aim of the present research and the factors influencing students' choices of chemical movies are analysed.

Mayer has shown that students who listen to (or read) explanations that are presented solely as words are unable to remember most of the key ideas and they experience difficulties in using what was presented to solve new problems (Mayer, 1997, 1999). Having text and spoken word produces a large multimedia effect on deep learning, which has been tested on problem solving transfer. This effect can be interpreted by the cognitive theory of multimedia learning, which states that multimedia cause learners to use both visual and verbal channels and not only one of these channels.

\section{Research questions}

This contribution tries to answer to two questions: (i) How chemical movies are chosen by students interacting with a task? (ii) How difficult is it to memorize conceptual information from such movies? The answers to these questions are to be presented in three steps: (i) the description of the research tool (a hypermovie), (ii) the interaction of students dealing with a hypermovie and a series of questions, and (iii) the memorization of concepts from movies after seven days. 


\section{Description of the hypermovie}

Hypermovie is a neologism that we adopted to represent a bank of movies connected by links. The uses of this neologism can be traced in a search engine as Google ${ }^{\mathrm{TM}}$ and always stand for interactive movies (see for example Melzer et al., 2004).

We created two ways for navigating in our hypermovie (Figure 1). One is based on a tree diagram with three headers (acids, bases, acid-base pairs); each header may open to several sub-headers and each of them may open to several titles of movies (Pekdağ \& Le Maréchal, 2003a). Activation of a title leads to a movie-page with a button on the left and a list of words on the right. The button can activate a movie and the list of words consists on chemical concepts extracted from the narration of the movie. The second possibility of navigation uses these chemical concepts that form a list of links. Each of these conceptual links leads to a new page with a list of movies the narrations of which contain this concept.

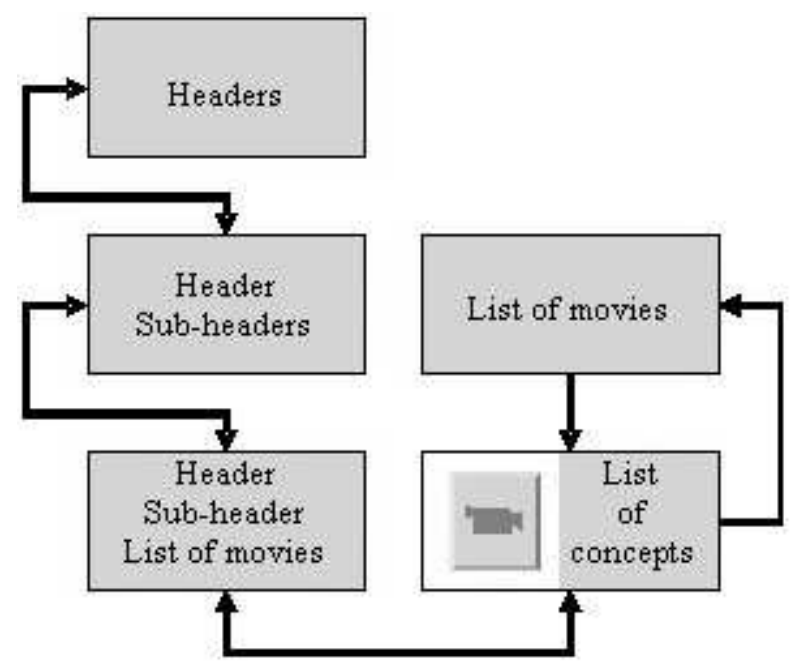

Figure 1 - Representation of the two ways of navigating the hypermovie: left from the tree diagram, right from conceptual links.

The 34 one to three minute long movies of the bank were home made after a conceptual analysis of both students' curriculum and students' conceptions. They are short to be perceived as a one piece unit best studied in a single session (Capsi et al., 2005). They can contain the video of a chemical experiment, an animation, commentaries about data, etc.

Movies were created with a careful relation between narrations and pictures, respecting as much as possible Mayer's four conditions (1989): to be helpful (1) the text must describe a cause-and-effect system; (2) the illustrations must reasonably depict the system or process under consideration; (3) appropriate outcome measures must be selected; and (4) the learners must be inexperienced with respect to the targeted content domain.

The movies were created using the main kinds of picture styles: (i) video, which is appropriate for describing events such as chemical experiments; (ii) animation, much adapted for molecular display; (iii) slide show when data or photos are to be commented. Pictures were designed as representational (e.g. pictures such as an experiment that seems to be described by the narration), organisational (e.g. pictures that provide a useful structural framework for example in the case of tables of data) and interpretational when (e.g. pictures that help to clarify a difficult narration) in Levin's terminology first used to describe storybook illustration (Levin, 1981; Carney \& Levin, 2002). The two other functions of picture: decorational (pictures simply decorate the screen, bearing little or no relationship to the narration) and transformational (pictures that provide mnemonic aids) do not appear in our movies. 


\section{Working with the hypermovie}

This part presents a first experiment in relation to both research questions.

\subsection{Methodology}

The method to collect data and the way to analyse them are detailed here. Although the hypermovie is a new research tool, proven methods were used in our work.

\subsubsection{Collecting data}

A series of concept oriented open questions relative to acids and bases and an access to the hypermovie were given to six pairs of students who were video recorded. Each pair of students produced a handout that was collected. The one hour discussions of two pairs were transcribed and analyzed. The experiment was conducted several months after the students had their regular courses on acids and bases.

Asking questions to students was way to have them interacting and therefore led to the recorded discussion we had expected for data analysis. It was also a way to have them watching the movies with an active role (Gourgey, 1998). A few questions are given below as examples with the results. They have no "whys" nor "whats" relations to the movies. They would have provoked an interrogative elaboration of the meaning of the movie (Carney \& Levin, 2002), which was not intended. Instead, questions were open for students to process information of the movies.

\subsubsection{Analyzing data}

The first analysis of data consisted of finding relations between the choice of a movie and students' activities. Students' choices were categorized as: (i) choice of a movie that had already been watched at least once; (ii) choice of a movie prescribed by the task, (iii) choice of a movie with a surface feature; (iv) choice of a movie for a reformulation of the question of the task, or for a new question.

We considered that students chose a movie from a surface feature when there was at least one common word in the question and in the title of a movie. Using surface features to solve problems is a classic novices' behaviour unlike experts who group them by their underlying principles based on laws of physics (Gourgey, 1998). Novices often use the surface features (such as colour, motion, labels, etc.) of the displays to try to build an understanding of chemical phenomena (Kozma, 2003).

Telling apart the reformulation of the question and the occurring of a new question is important as questions generated by students trace an active thinking and a better learning (Hartman, 1994).

\subsection{RESUlTS AND DISCUSSION}

As expected, students could not answer the questions without watching movies. They watched movies that were prescribed as well as others. The numbers of movies in each category are given in table 1 . 


\begin{tabular}{|l|c|c|c|c|}
\hline students & $\begin{array}{c}\text { re-watching } \\
\text { of a movie }\end{array}$ & $\begin{array}{c}\text { prescribe } \\
\text { movies }\end{array}$ & $\begin{array}{c}\text { surface } \\
\text { feature }\end{array}$ & $\begin{array}{c}\text { reformulation } \\
\text { or new question }\end{array}$ \\
\hline E/F & 2 & 4 & 7 & 2 \\
\hline $\mathbf{M} / \mathbf{B}$ & 5 & 4 & 4 & 1 \\
\hline total & $7(24 \%)$ & $8(28 \%)$ & $11(38 \%)$ & $3(10 \%)$ \\
\hline
\end{tabular}

Table 1 - Number of movies chosen by students' pair E/F and M/B in each category.

Students did not watch a movie for another reason than those of our categories. From Thévenot's point of view (1998), an action can be done either to accommodate local conditions (as watching a prescribe movie) or with an objective (our other categories). Whatever the reasons of the choice of a movie may be, students did not watch a movie by chance; the choice was individually/collectively led by a teleological need. Providing movies as a resource for students seems therefore pertinent.

The high percentage of movies chosen from surface features is not surprising as it has for long been known that it is the way novices construct mental representations of physical situations (Chi et al., 1981; Larkin et al., 1980). However, the case of the choice of a movie had probably not been described before. The following example helps to understand how such a choice may happen during students' discussions. The question students had to answer is: "Chlorhydric acid is added to a sodium acetate solution. Explain why a vinegar smell appears?". The choice of the movie "Effect of adding acid on $\mathrm{pH}$ " is surface feature driven indeed, as the question deals with addition of acid such as the title of the movie. Moreover, students had spent 5 min $5 \mathrm{~s}$ exploring 17 other concept links before they clicked on "Effect of adding acid on $\mathrm{pH}$ " and during this time, no other concepts that those of the links had been put into the discussion.

F yea / in the acid-base pair (F mentioned the link "acid/base pair")

E why for / wait

F here for / click on it once here (F showed the link "release of $\mathrm{H}^{+}$")

$\mathrm{E}$ here close the link release of $\mathrm{H}^{+}$

F let's go here (F mentioned the link "properties of acids")

$\mathrm{E}$ it was the first menu

F yeah

E click on the menu

F here in (F showed the link "acid/base pair")

E acid/base pair (E read the link)

F let's go here / then we may have the pair (F showed the link)

E chlorhydric acid (E read the question and clicked on the link)

F look at these link / conjugated form (F read the link "Conjugated form") / go in half equation (F mentioned the link "half equation")

E ho no/where do you want to go here

F I don't know may be in conjugated form (F read the link "conjugated form")

Such behaviour toward concepts that are read on links and never related to any personal knowledge is clearly a surface feature one (Kozma \& Russell, 1997). Reading or mentioning 17 links within $5 \mathrm{~min} 5 \mathrm{~s}$ (one every $18 \mathrm{~s}$ as an average) before deciding to watch 
one film is another criteria of inefficiency of such behaviour. Nevertheless, the students explored the hypermovie with an objective. They did not follow a prescription and were in the teleological Thévenot's level (1998).

Rewording a question is a better way to answer it. After reading the question "How is it possible to represent what happens in solution when sodium acetate is introduced in water?" one student suggested writing an equation, which is one of the possible representations indeed. She could have proposed a drawing at the molecular level or at the macroscopic one but she decided to propose the symbolic one (Johnstone, 1993). Such a reformulation of the question is not deep but it led to the consultation of the movie "General notation of half equations". Students used their knowledge to transform the question to find a movie unlike they did in the cases of surface features. These students therefore actively interacted with the question and tried to clarify the purpose of reading (Gourgey, 1998). Such behaviour reveals the beginning of an understanding.

An interesting but broad question is how much knowledge can be reused from a movie. The number of times a given movie was watched is interesting to this respect. Table 1 shows that one every four movies was watched at least twice. One of the movies "Effect of adding acid on $\mathrm{pH}$ ", although it was not longer than others, was watched several times by the 6 pairs of students.

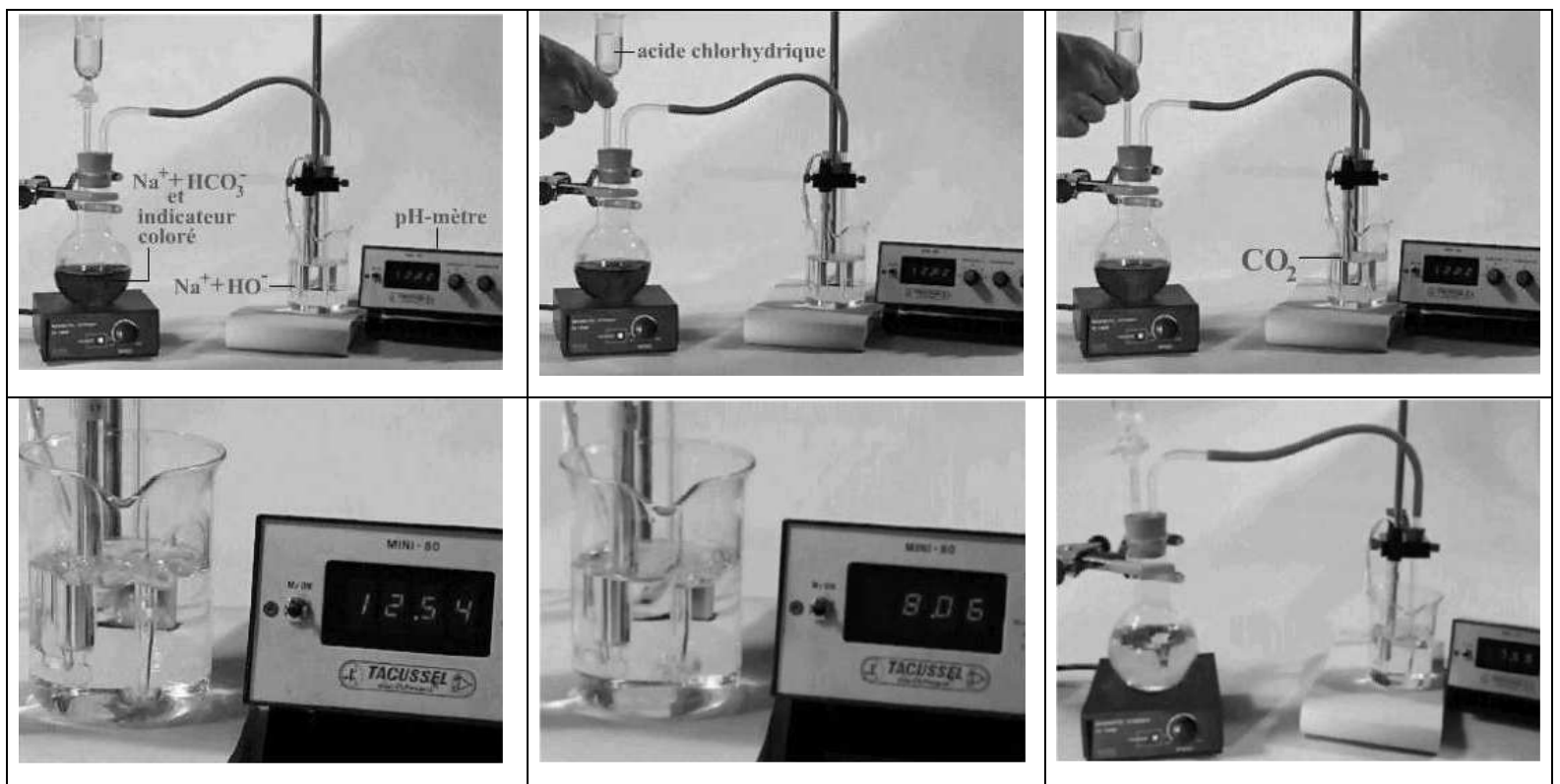

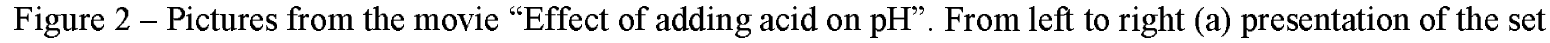
up; (b) chlorhydric acid addition; (c) $\mathrm{CO}_{2}$ bubbles in the beaker; (d) close up on the bubbles; (e) close up on the decrease of the $\mathrm{pH}$; (f) colour change of the $\mathrm{pH}$ indicator in the flask.

Two factors can be proposed to understand the reason of its low memorisation. The first one is the number of non perceptible events such as the reagents of the chemical reactions reacting together and the gas transfer from a flask to a beaker by means of a rubber hose. Although all of these non perceptible events had a visible counterpart (a liquid addition for the reaction $\mathrm{H}^{+}+\mathrm{HCO}_{3}{ }^{-}-$Fig. $2 \mathrm{~b}-$, a bubbling during the $\mathrm{CO}_{2}$ transfer - Fig. $2 \mathrm{~d}-\mathrm{a} \mathrm{pH}$ 
change for the reaction $\mathrm{CO}_{2}+\mathrm{HO}^{-}-$Fig. $2 \mathrm{e}-$, and a colour change for the reaction of the $\mathrm{pH}$ indicator - Fig.2f), the capacity of decoding and processing these perceptible events in the students' working memory must have been overloaded (Chandler \& Sweller, 1991; Baddeley, 1992). Constructivist theory tells us that meaningful learning requires the learner to actively select relevant information, organise them into coherent representation and integrate them with other knowledge (Mayer, 1996). The flow of new information from the video did not allow these selections, organisation and integration processes that could have led to memorise the non perceptible events

Another interpretation of low memorisation may be given from the dual coding theory. This theory states that visual and verbal materials are processed in different processing systems (Clark \& Paivio, 1991; Paivio, 1986). Eyes and Ears produce pictorial and verbal representations respectively and a more meaningful learning occurs when both representations interact with prior knowledge (Mayer \& Moreno, 2002). The non perceptible events displayed in the movie that was repeatedly watched by all students were commented by a narration. Nevertheless, only the verbal processing system was activated as the chemical reactions and gas transfer were not directly perceptible and students could not build an immediate representation from the visual processing system.

\section{Seven day memorisation}

Another memory-oriented experiment was performed to better understand the memorisation difficulties in the case of chemical movies

\subsection{METHOD}

Seven movies from the hypermovie and a few questions were given to two other pairs of students (Gl-Gu and Ga-Je) of the same level as those of the previous experiment. They spent approximately $45 \mathrm{~min}$.

Movies were of different kinds: animations ("Dissociation - microscopic animation"; " $\mathrm{HCl}$, a Bronsted acid"; "pH of Vinegar"), video ("Vinegar and sodium hydroxide") or slide show ("Acid rains"; Air pollution; "Dissociation of $\mathrm{HCl}$ and $\mathrm{CH}_{3} \mathrm{COOH}$ "). For each movie, two slightly different narrations were made. Each narration started by the same sentences. The same ideas were then developed in both narrations, but one used a descriptive vocabulary of whatever is perceptible on the screen whereas the other frequently uses the chemical vocabulary. For example, the narrations of the movie "Dissociation of $\mathrm{HCl}$ and $\mathrm{CH}_{3} \mathrm{COOH}$ " were:

\section{Perceptible narration}

Acids may release a hydrogen ion. The connected white and green balls represent a hydrogen chloride molecule $\mathrm{HCl}$. The separation of the white ball represents the release of a $\mathrm{H}^{+}$ion. It illustrates the acidic property of $\mathrm{HCl}$ represented by a half equation written under the balls. This other

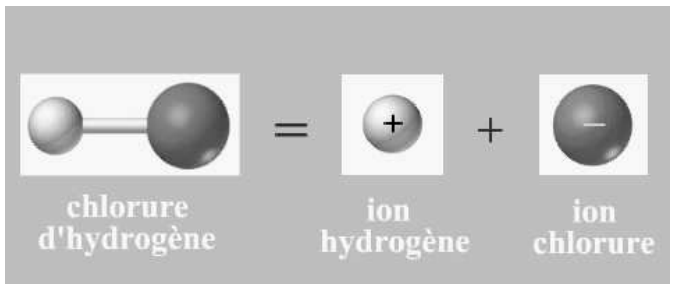


formula is a more complex acid: acetic acid. One of the white balls can also be separated from the rest of the assembly. It is again represented by a half equation written under the balls.

Non perceptible narration

Acids may release a hydrogen ion. It is the case of hydrogen chloride. When a $\mathrm{H}^{+}$ion is released, there is simultaneously formation of a chloride anion. It is also the case of acetic acid. When a $\mathrm{H}^{+}$ion is released, the acetic acid releases also an acetate ion.

The use of perceptible and non perceptible vocabulary in modelling has been described and can affect students' comprehension (Le Maréchal, 1999). Such a modelling approach also provides keys to analyse movies with educational perspectives (Pekdağ \& Le Maréchal, 2003b). In our case, the perceptible features of narrations were used to test their influences on memorisation.

Seven days after this simplified version of the previous experiment, we individually asked the four students to put down what they recalled from the movies with the following questions:

Which movies do you remember and what were their topics (answer with as many details as possible)? Briefly depict with drawing and/or with sentences what you remember from the movies

In this experiment the students watched the same movies in the same order whereas in the previous one, they watched the movie they needed. Interpretation of the memorisation is therefore simpler. For example, it is now possible to test the influence of the order in the casting of the movies.

\subsection{RESULTS AND DISCUSSION}

Table 2 shows the results of 7 day memorisation analysis.

\begin{tabular}{|c|c|c|c|c|c|c|}
\hline $\begin{array}{c}\text { Casting } \\
\text { order }\end{array}$ & Title of movies & Kind of movie & Gl & Gu & Ga & Je \\
\hline 1 & Dissociation - microscopic animation & Animation & P & (p) & (r) & (r) \\
\hline 2 & Acid rains & Slide show & P & P & R & R \\
\hline 3 & Air pollution & Slide show & P & P & (r) & R \\
\hline 4 & Dissociation of HCl and CH3COOH & Slide show & (r) & R & P & P \\
\hline 5 & HCl, a Bronsted acid & Animation & $(\mathrm{r})$ & R & (p) & P \\
\hline 6 & pH of Vinegar & Animation & (r) & R & P & P \\
\hline 7 & Vinegar and sodium hydroxide & Video & R & R & (p) & P \\
\hline
\end{tabular}

Table 2 - Memorisation of movies according to their kinds of pictures and narrations. $P$ stands for a perceptible narration and $\mathrm{R}$ for a non perceptible one. Higher case with no bracket stands for movies that were recalled. Movies had been cast in the order of the first column.

From table 2, it appears that the casting order (recency effect), the kinds of pictures (animation, slide show or video) and the kinds of narrations (perceptible or not) have no real 
influence on the seven day memorisation. We therefore turned our analysis to the way students recalled the movies. We found out that students used information from the picture more that from the text to answer our questions. Students produced description of pictures with their own words, using only some of the concepts that were in the narrations, and few others. For example, the student Je produced the following comments about his recall of the movie "Acid rains":

The 2 nd movies talked about acid rains and their effects on nature. We noticed that acid rains attack leaves of trees and erode statues. We were also explained how rain becomes acidic (it comes from emissions of factories then clouds get the acidity of gas)

Bold face words came out of the narration of the movie, but italic words were not. Instead, factories with their smokes was shown twice, and once with $\mathrm{SO}_{2}$ and $\mathrm{NO}_{2}$ symbols (Figure 3). Students did remember part of the picture they commented with no precise recall of the corresponding narration.

For the whole four students, 39 words such as chemical concepts and nouns related to them (i.e. leaves, trees or statues in the above example) belonged both to students' descriptions and narrations whereas 51 were used to describe pictures of the movie. Such results confirm that memorisation of pictures is better than memorisation of texts (Dubois \& Tajariol, 2001). We also found that $58 \%$ of the 51 recalls of pictures came out of iconic representations, $23 \%$ from videos, $15 \%$ from photos, and $4 \%$ from symbols. This information may be used by educational movie producers for they chose the more efficient way to represents concepts to be recalled. For example, we suggest symbols not be over used although it is the most common way to represent chemistry.

The better remembering of picture over text does not mean that picture alone is responsible for memorisation. Pictures alone would not even be correctly understood due to their polysemy (Joly, 1994). The narration specifies the meaning of the pictures. The remembering of pictures in the case of movies can be associated to the role of pictures in storybooks; it establishes the setting and reinforces the text, it motivates the reader and serves as a mental scaffold (Fang, 1996). Details of the pictures of the movie such as the factories could be remembered although they were not mentioned in the narration, just as pictures in storybooks may go beyond this role by adding details (e.g., Stewig, 1992).

\section{Conclusion and implication in teaching}

Instructional movie designers and teachers who may involve movies in their teaching should know basic principles that rule the uses of movies in education. Surface features are often the starting point for grasping new knowledge and should be selected before being proposed to students. The use of movies in teaching should be coupled with tasks that force students to use the information presented by the movies. Such information should therefore not be related to too many non perceptible events to avoid low memorisation. Instead, important information should better be both presented in the picture and in the narration to take advantage of the dual coding and multimedia effects. Although symbols are paramount in 
chemistry, their uses in movies are questionable as it leads to little recall by learners. Now that many chemical movies are available, they may be organised on hypermedia for students to use them with profit. The links has therefore be informative as the knowledge that can be embedded in the links is usable by learners even though surface feature cannot be avoided.

\section{References}

Baddeley, A. (1992). Working memory. Science, 255, 556-559.

Capsi, A., Gorsky, P. \& Privman, M. (2005). Viewing comprehension: Students' learning preferences and strategies when studying from video. Instructional Science, 33, 31-47.

Carney, R. N. \& Levin J. R. (2002). Pictorial illustrations still improve students' learning from text. Educational Psychology Review, 14(1), 5-26.

Chandler, P. \& Sweller, J. (1991). Cognitive load theory and the format of instruction. Cognition and Instruction, 8(4), 293-332.

Chi, M., Feltovich, P. \& Glaser, R. (1981). Categorization and representation of physics problems by experts and novices. Cognitive Science, 5, 121-152.

Clark, J. M. \& Paivio, A. (1991). Dual coding theory and education. Educational Psychology Review, $3(3), 149-210$

Dubois, M. \& Tajariol, F. (2001). Présentation multimodale de l'information et apprentissage (Multimodal presentation of information and learning). In E. De Vries, J.-Ph. Pernin \& J.-P. Peyrin (Eds.), Hypermédias et Apprentissages 5, 197-209. Actes du cinquième colloque (Grenoble, 9-11 avril 2001). Paris, INRP.

Fang, Z. (1996). Illustrations, text, and the child reader. What are pictures in children's storybooks for? Read Horizons, 37, 130-142.

Gourgey, A. F. (1998). Metacognition in basic skills instruction. Instructional Science, 26(1-2), 81-96.

Hartman, H. J. (1994). From reciprocal teaching to reciprocal education. Journal of Developmental Education, 18(1), 2-8.

Jacobsen. J. J., Moore J. W., Zimmerman, J. F. \& Browne, L. M. (2002). Chemistry Comes Alive ! Volume 6: Abstract of Special Issue 30, a CD-ROM of Laboratory Techniques. Journal of Chemical Education, 79, 1381-1384.

Joly, M. (1994). L'image et les signes. Approche sémiologique de l'image fixe. Paris, Nathan.

Johnstone, A. H. (1993). The development of chemistry teaching: A changing response to changing demand. Journal of Chemical Education, 70(9), 701-705.

Kozma, R. (2003). The material features of multiple representations and their cognitive and social affordances for science understanding. Learning and Instruction, 13(2), 205-226.

Kozma, R. B. \& Russell, J. (1997). Multimedia and understanding: Expert and novice responses to different representations of chemical phenomena. Journal of Research in Science Teaching, 34(9), 949-968.

Larkin, J., McDermott, J., Simon, D. \& Simon, H. (1980). Expert and novice performance in solving physics problems. Science, 208, 1335-1342.

Le Maréchal, J.-F. (1999). Modelling student's cognitive activity during the resolution of problems based on experimental facts in chemical education. In J. Leach \& A. C. Paulsen (Eds.), Practical Work in Science Education, 195-209. Dordrecht, Kluwer. 
Levin, J. R. (1981). On functions of pictures in prose. In F. J. Pirozzolo \& M. C. Wittrock (Eds.), Neuropsychological and Cognitive Processes in Reading, 203-228. New York, Academic Press.

Mayer, R. E. (1989). Systematic thinking fostered by illustrations in scientific text. J. Educ. Psychol., 81, 240-246.

Mayer, R. E. (1996). Learning strategies for making sense out of expository text: The SOI model for guiding three cognitive processes in knowledge construction. Educational Psychology Review, 8 , 357-371.

Mayer, R. E. (1997). Multimedia learning: Are we asking the right questions? Educational Psychologist, 32(1), 1-19.

Mayer, R. E. (1999). Multimedia aids to problem-solving transfer. International Journal of Educational Research, 31, 611-623.

Mayer, R. E. \& Moreno, R. (2002). Aids to computer-based multimedia learning. Learning and Instruction, 12(1), 107-119.

Melzer, A., Hasse, S., Jeskulke, O., Schön, I. \& Herczeg, M. (2004). The interactive and multiprotagonist film: A hypermovie on DVD. In M. Rauterberg (Ed.), Entertainment Computing ICEC 2004, 193-203. Third International Conference Eindhoven, The Netherlands.

Paivio, A. (1986). Mental representations: A dual coding approach. Oxford, UK: Oxford University Press.

Pekdağ, B. \& Le Maréchal, J.-F. (2003a). Hyperfilm : Un outil de recherche en didactique de la chimie. In C. Desmoulins, P. Marquet \& D. Bouhineau (Eds.), Environnements Informatiques pour l'Apprentissage Humain, 547-550. Actes de la conférence EIAH (Strasbourg, 15-17 avril 2003). Paris, ATIEF et INRP.

Pekdağ, B. \& Le Maréchal, J.-F. (2003b). Influence of the relations between picture and text of chemical education films on conceptual change. In D. Krnel (Ed.), Proceedings of the Sixth ESERA Summer-school (Radovljica, Slovenia, 25-31 August 2002), 204-211. Ljubljana, University of Ljubljana Press.

Pekdağ, B. \& Le Maréchal, J.-F. (submitted). Films et multimédias dans l'enseignement de la chimie. Didaskalia.

Rouda, R. H. (1973). Student-produced videotapes in a physical chemistry laboratory course. Journal of Chemical Education, 50, 126-127.

Slabaugh, W. H. \& Hatch, C. V. (1958). General chemistry via television. Journal of Chemical Education, 35(1), 95-96.

Stewig, J. W. (1992). Reading pictures, reading text: Some similarities. New Advocate, 5(1), 11-22.

Thévenot, L. (1998). Pragmatiques de la connaissance. In A. Borzeix, A. Bouvier \& P. Pharo (Eds.), Sociologie et connaissances, nouvelles approches cognitives, 101-139. Paris, CNRS Editions. 